\title{
A Mitochondrial Import Receptor for the ADPIATP Carrier
}

\author{
Thomas Söllner,* Rupert Pfaller," Gareth Griffiths, ${ }^{\dagger}$ \\ Nikolaus Pfanner," and Walter Neupert" \\ * Institut für Physiologische Chemie \\ Universität München \\ D-8000 München 2 \\ Federal Republic of Germany \\ † European Molecular Biology Institute \\ D-6900 Heidelberg \\ Federal Republic of Germany
}

\begin{abstract}
Summary
We have identified a mitochondrial outer membrane protein of $72 \mathrm{kd}$ (MOM72) that exhibits the properties of an import receptor for the ADP/ATP carrier (AAC), the most abundant mitochondrial protein. Monospecific antibodies and Fab fragments against MOM72 selectively inhibit import of AAC at the level of specific binding to the mitochondria. AAC bound to the mitochondrial surface is coprecipitated with antibodies against MOM72 after lysis of mitochondria with detergent. MOM72 thus has a complementary function to that of MOM19, which acts as an import receptor for the majority of mitochondrial proteins studied so far but not for the AAC. The import pathway of the precursor of MOM72 appears to involve MOM19 as receptor.
\end{abstract}

\section{Introduction}

Transport of nuclear-encoded proteins into cellular organelles occurs along complex pathways. A major intriguing problem is how completely or incompletely synthesized precursor proteins in the cytosolic compartment are recognized by the target organelle (Wickner and Lodish, 1985; Walter and Lingappa, 1986; Attardi and Schatz, 1988; Hartl et al., 1989; Pfanner and Neupert, 1989). The process of initial binding and insertion has been studied in the case of mitochondria at some depth using a variety of precursor proteins. Rather detailed results were obtained with the precursor to the ADPIATP carrier (AAC) (summarized in Pfanner et al., 1988), the most abundant mitochondrial membrane protein (Klingenberg, 1985). $A A C$ is synthesized as cytosolic precursor protein without amino-terminal peptide extension (Zimmermann et al., 1979; Arends and Sebald, 1984). Targeting signals in non-amino-terminal regions of the mature protein part direct the precursor to mitochondria (Pfanner et al., 1987b; Smagula and Douglas, 1988). Studies with Neurospora crassa (N. crassa) mitochondria allowed dissection of the import pathway of AAC from the cytosol (stage 1) into the mitochondrial inner membrane (stage 5) into a series of consecutive steps (Zwizinski et al., 1983; Schleyer and Neupert, 1984; Pfanner and Neupert, 1985, 1987; Pfanner et al., 1987a, 1987d; Pfaller et al., 1988; Söllner et al., 1988): in the first step, the precursor protein binds to a protease-sensitive component on the mitochondrial sur- face assumed to function as receptor site (stage 2); then, the precursor protein is inserted into the outer mitochondrial membrane (stage 3 ) at a site termed "general insertion protein"; the initial insertion into the inner membrane in a membrane potential-dependent step (stage 4) is followed by complete translocation of AAC into the inner membrane and assembly to the dimeric form (stage 5).

Recently, we identified a $19 \mathrm{kd}$ protein of the mitochondrial outer membrane, termed MOM19, as import receptor for most precursor proteins studied, including all precursor proteins that carried an amino-terminal extension sequence (presequence) (Söllner et al., 1989). However, the precursor of AAC did not appear to use the MOM19 as receptor. This raised the possibility that mitochondria may carry two distinct receptor sites with different specificity. To identify a putative import receptor for AAC, we investigated the effect of specific antibodies directed against various proteins of the outer membrane (Söllner et al., 1989) on the import of AAC into isolated mitochondria. We detected a protein of $72 \mathrm{kd}$, termed MOM72, that apparently exhibits the properties of a high affinity import receptor for AAC. The existence of at least two distinct receptor proteins raises important implications concerning the biogenesis of nuclear-encoded mitochondrial proteins.

\section{Results}

\section{The Mitochondrial Outer Membrane} Protein MOM72

We previously prepared a collection of specific antibodies against most of the $\sim 25$ polypeptides found in the outer membrane of $\mathrm{N}$. crassa mitochondria (Söllner et al., 1989). To identify a putative import receptor for the precursor of AAC, immunoglobulins $\mathrm{G}$ (IgGs) prepared from various rabbit antisera were prebound to isolated mitochondria, and import of AAC was investigated. Only antibodies directed against an outer membrane protein with the apparent molecular mass of $72 \mathrm{kd}$ (MOM72) significantly inhibited import of AAC (see below). We thus characterized the properties of MOM72 in greater detail.

The protein band corresponding to MOM72 is indicated in Figure 1A, which shows the protein pattern of purified mitochondrial outer membrane after resolution on an SDS-polyacrylamide gel. The antibodies against MOM72 were monospecific both in immunoprecipitation of MOM72 from ${ }^{35}$ S-labeled mitochondria (Figure $1 \mathrm{~B}$ ) and in immunodecoration of mitochondrial proteins transferred to nitrocellulose paper (Figure 1C). MOM72 behaves as integral membrane protein: it was not released from the mitochondrial membranes after sonication of mitochondria at various concentrations of salt (Figure 2A), and it was not extracted from the membranes after treatment of mitochondria at alkaline $\mathrm{pH}$ (sodium carbonate [pH 11.5]; Fujiki et al., 1982a, 1982b) (Figure 2B). MOM72 is exposed on the mitochondrial surface as evidenced by its accessibility to low concentrations of various proteases (Figure $2 \mathrm{C}$; these protease treatments do not affect the outer 


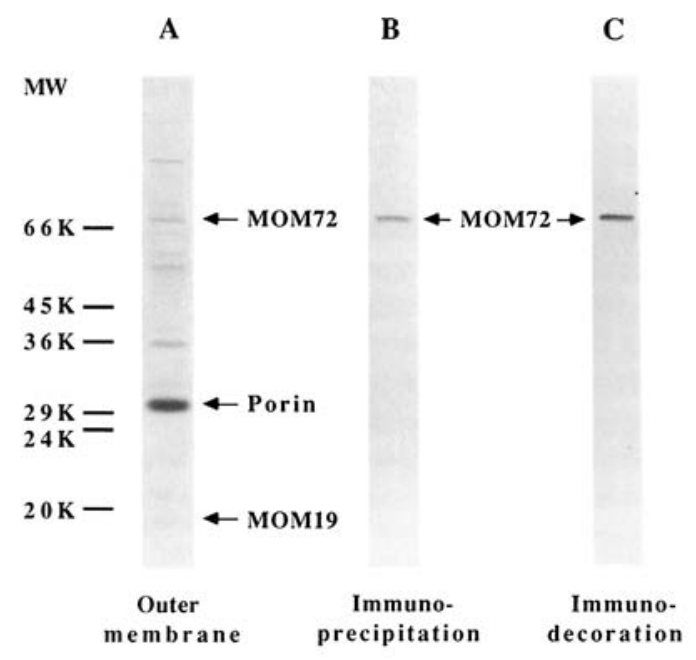

Figure 1. Identification of the Mitochondrial Outer Membrane Protein MOM72

(A) Protein pattern of mitochondrial outer membrane of N. crassa. Purified mitochondrial outer membrane ( $30 \mu \mathrm{g}$ of protein) (Söllner et al., 1989) was resolved by SDS-PAGE, and proteins were stained with Coomassie blue R-250.

(B) Immunoprecipitation with anti-MOM72 antibodies. ${ }^{35} \mathrm{~S}$-labeled mitochondria ( $50 \mu \mathrm{g}$ of protein) were lysed in SDS-containing buffer ( $2 \%$ SDS, $60 \mathrm{mM}$ Tris- $\mathrm{HCl}$ [pH 6.8]). After 20-fold dilution with Triton X-100containing buffer ( $1 \% \mathrm{v} / \mathrm{v}$ Triton $X-100,300 \mathrm{mM} \mathrm{NaCl}, 5 \mathrm{mM}$ EDTA, 10 $\mathrm{mM}$ Tris- $\mathrm{HCl}[\mathrm{pH} 7.5])$. immunoprecipitation was performed as described (Schleyer et al., 1982). The immunoprecipitate was subjected to SDS-PAGE. A fluorogram of the dried gel is shown.

(C) Immunodecoration with anti-MOM72 antibodies. Mitochondrial proteins $(50 \mu \mathrm{g})$ were separated by SDS-PAGE, electrotransferred to nitrocellulose, and immunolabeled with antiserum against MOM72. Bound antibodles were visualized with the anti-rabbit IgG-alkaline phosphatase conjugate procedure (Blake et al., 1984).

membrane barrier [Hartl et al., 1986, 1987; Schwaiger et al., 1987]) and to specific antibodies added to mitochondria (Figure 2D). MOM72 is present at $\sim 2-5$ pmol per $\mathrm{mg}$ of mitochondrial protein as assessed by the abundance of the Coomassie blue-stained protein band, similar to the abundance of MOM19 (Söllner et al., 1989). The antibodies against MOM72 show a (weak) cross-reactivity with an outer membrane protein of similar apparent size of yeast mitochondria (Saccharomyces cerevisiae) that might thus represent the equivalent of MOM72 $(H$. F. Steger, T. S., N. P., and W. N., unpublished data).

For localization of MOM72 by electron microscopy, cryosections of $N$. crassa mitochondria were labeled with antibodies directed against MOM72 followed by binding of protein A-gold particles. Almost all of the gold particles were in close vicinity to the outer mitochondrial membrane (Figure 3), confirming that MOM72 is an outer membrane protein. To demonstrate that MOM72 is exposed on the mitochondrial surface, mitochondria were preincubated with antibodies against MOM72 and labeled with protein A-gold particles prior to fixation and processing for electron microscopy. Figure 4 shows that MOM72 is accessible to added antibodies, thus confirming the biochemical results of Figure 2D. The concentration of gold particles in regions of close contact between both mito- chondrial membranes (corresponding to $\sim 15 \%$ of the surface of the outer membrane) is about 5-fold higher than in the rest of the outer membrane, indicating an enrichment of MOM72 in contact sites (Figure 4, arrowheads). This is confirmed by a detailed quantitative analysis of the localization of various components of the mitochondrial import machinery, which will be presented elsewhere (G. G., C. Hergersberg, T. S., N. P., and W. N., unpublished data). The distribution of MOM72 would fit well to the proposed role of MOM72 as an import receptor for the precursor of AAC, which is imported at contact sites (Pfanner and Neupert, 1987; Pfanner et al., 1987a).

\section{Antibodies against MOM72 Inhibit Import of AAC into Mitochondria}

Antibodies directed against MOM72 were prebound to isolated N. crassa mitochondria. Radiolabeled precursor of AAC, synthesized in rabbit reticulocyte lysate, was added, and import was performed at $25^{\circ} \mathrm{C}$. Import of AAC was measured by protection of the imported protein against high concentrations of proteinase $\mathrm{K}$ added to the mitochondria (Schleyer and Neupert, 1984; Pfanner and Neupert, 1987). IgGs against MOM72 inhibited import of AAC, while control antibodies, directed against porin (the major outer membrane protein), MOM19, or from preimmune sera, had no significant effect (Figure 5A). A similar result was obtained when monovalent Fab fragments were used (Figure 5B). Import of other precursor proteins, such as porin. Fe/S protein of the cytochrome bc ${ }_{1}$ complex, and apocytochrome $c$, was practically uninhibited by antiMOM72 antibodies (Figure 5C). Porin and Fe/S protein were shown to employ MOM19 as import receptor (Söllner et al., 1989), whereas apocytochrome c does not use a protease-accessible surface receptor (Nicholson et al., 1988; Stuart et al., 1990).

Inhibition of import of AAC by anti-MOM72 antibodies is apparently caused by the blocking of a mitochondrial surface component. First, antibodies against MOM72 did not recognize the precursor of AAC itself (data not shown), excluding the trivial possibility that the cytosolic precursor of AAC is inactivated by the antibodies. Second, we used the observation that a residual import ("bypass import") of mitochondrial precursor proteins can occur in the absence of receptor sites, i.e., into mitochondria pretreated with protease (Pfaller et al., 1989). Anti-MOM72 antibodies did not inhibit the bypass import of AAC (Figure 5D), indicating that binding of antibodies to a protease-sensitive component on the mitochondria is required for inhibition.

\section{Antibodies against MOM72 Inhibit Specific Binding of AAC to the Mitochondrial Surface}

Which step of the import pathway of AAC depends on MOM72? The exposure of MOM72 on the mitochondrial surface may suggest that it acts at an early stage of protein translocation. The selective inhibition of AAC import by antibodies against MOM72 would be in agreement with the properties expected of a putative import receptor (Pfaller et al., 1988; Söllner et al., 1989).

To further analyze the role of MOM72, we made use of translocation intermediates that can be generated on the 

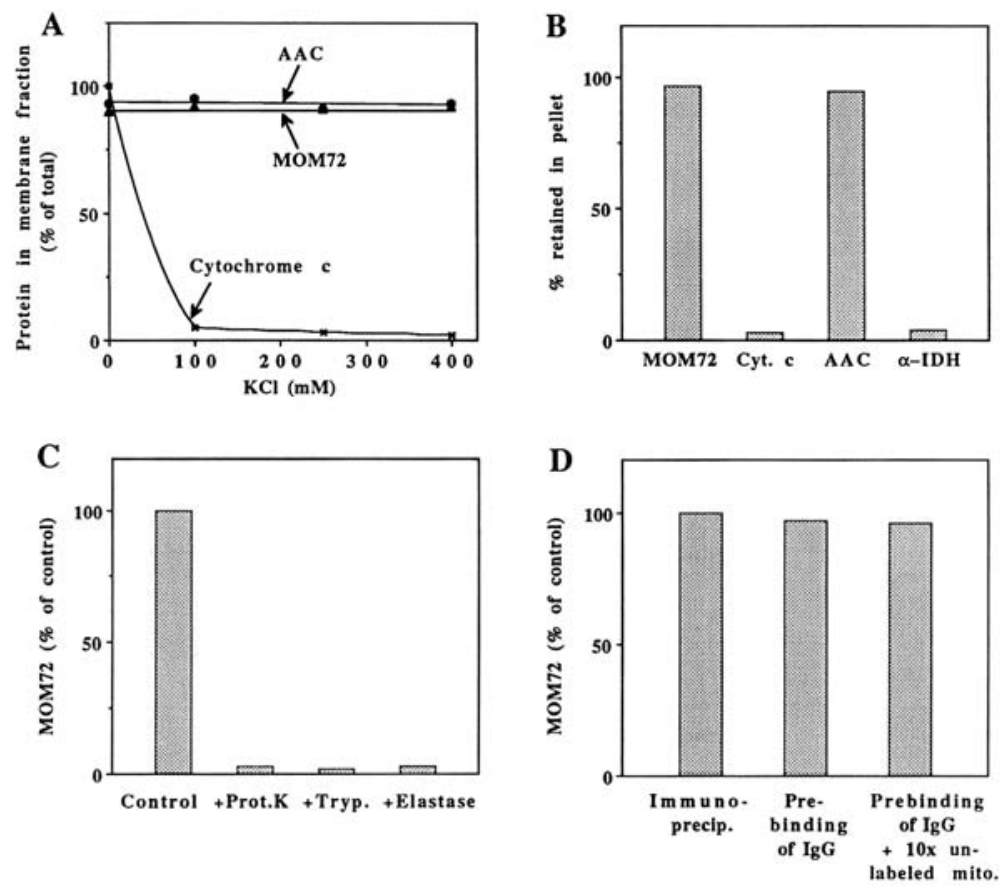

Figure 2. MOM72 Is an Outer Membrane Protein Exposed on the Mitochondrial Surface

(A) MOM72 is not released from mitochondria by salt and sonication. Mitochondria $(200 \mu \mathrm{g}$ of protein per $\mathrm{ml}$ of SEM) were sonified in the presence of PMSF $(1 \mathrm{mM})$ and different amounts of $\mathrm{KCl}$, as described (Söllner et al., 1989). Membranes and supernatants were separated by centrifugation ( $60 \mathrm{~min}, 166,000 \times$ g). The samples were subjected to SDS-PAGE and analyzed by immunoblotting for ADP/ATP carrier (AAC, as marker for the inner membrane), cytochrome $c$ (as marker for soluble proteins), and MOM72. After decoration with $\left[{ }^{14} \mathrm{C}\right]$ protein $\mathrm{A}$, the autoradiogram was quantified by laser densitometry.

(B) MOM72 is membrane associated at $\mathrm{pH}$ 11.5. Mitochondria $(100 \mu \mathrm{g}$ of protein per $\mathrm{ml})$ were incubated in $100 \mathrm{mM} \mathrm{Na} \mathrm{CO}_{3}$ (pH 11.5) for $30 \mathrm{~min}$ at $0^{\circ} \mathrm{C}$. Separation of pellets and supernatants was performed as described (Hartl et al., 1986). Immunoblotting with antiserum against the a subunit of isocitrate-dehydrogenase ( $\alpha-I D H$, matrix), AAC (inner membrane), cylochrome $c$ (intermembrane space), and MOM72 , and quantitation were performed as described for (A).

(C) MOM72 is accessible to proteases added to mitochondria. Mitochondria (1 $\mathrm{mg}$ of protein per

$\mathrm{ml}$ ) were either left on ice (control) or incubated with $10 \mu \mathrm{g} / \mathrm{ml}$ proteinase $\mathrm{K}$ (+Prot $\mathrm{K}$ ) or $10 \mu \mathrm{g} / \mathrm{ml}$ trypsin (+Tryp.) for $20 \mathrm{~min}$ at $0^{\circ} \mathrm{C}$, or $10 \mu \mathrm{g} / \mathrm{ml}$ elastase (+Elastase) for $15 \mathrm{~min}$ at $25^{\circ} \mathrm{C}$. Following SDS-PAGE and immunoblotting for MOM72, quantitation was performed as described in (A). (D) MOM72 is accessible to antibodies in intact mitochondria. MOM72 was either immunoprecipitated (Immunoprecip.) as described in Figure 1B, or anti-MOM72 IgGs were prebound to ${ }^{35} \mathrm{~S}$ labeled mitochondria ( $50 \mathrm{\mu g}$ of protein) (Prebinding of lgG). Reisolated mitochondria were washed with SEM buffer and lysed in Triton X-100-containing buffer in the absence or presence of a 10-fold excess of nonradiolabeled mitochondria.

import pathway of AAC. Binding of AAC to its postulated surface receptor was functionally characterized as generation of the stage 2 intermediate of AAC (Pfanner and Neupert, 1987; Pfanner et al., 1987d; Pfaller et al., 1988; Söllner et al., 1988): AAC precursor was bound to the surface of mitochondria at low levels of ATP and in the absence of a membrane potential across the inner membrane. This binding depends on a protease-sensitive component on the mitochondria that is assumed to represent the receptor site. Binding to the stage 2 site is specific, as the precursor that accumulates at this site is able to follow the further import steps, such as insertion into the outer membrane (upon elevation of ATP levels) and transport into the inner membrane (upon reestablishing the membrane potential). We thus investigated whether MOM72 is required for the stage 2 binding of AAC. Antibodies (Figure $6 A$ ) or Fab fragments (Figures $6 B$ and $6 C$ ) against MOM72 bound to mitochondria indeed inhibited generation of the stage 2 intermediate of AAC.

None of the other import steps of AAC, such as insertion into the outer membrane and transport from the outer into the inner membrane (Pfanner and Neupert, 1987), is affected by antibodies against MOM72. Precursor of AAC was accumulated at the stage 2 site, anti-MOM72 antibodies were bound to the mitochondria, and further import of $A A C$ was allowed to occur. Figure $6 D$ shows that translocation of $A A C$ from the stage 2 site to its functional destination in the inner membrane (stage 5) was not inhibited.

\section{AAC Bound to the Mitochondrial Surface Is Coprecipitated with Antibodies against MOM72} Does MOM72 function as high affinity import receptor for AAC? To demonstrate direct functional interaction of MOM72 with the precursor of $A A C$, mitochondria carrying $A A C$ bound at the stage 2 site were lysed with detergent. Antibodies against MOM72 coprecipitated the precursor of AAC, whereas antibodies against either MOM19, porin, or from preimmune sera did not (Figure 7). This shows that AAC bound to the stage 2 site forms an immunoprecipitable complex with MOM72. As control, AAC imported into the inner membrane could not be coprecipitated with antibodies against MOM72 (Figure 7); the small amounts of $A A C$ in the immunoprecipitate correspond to the $5 \%$ $10 \%$ of $A A C$ that are still at the stage 2 site under these import conditions (Pfanner and Neupert, 1987; Pfanner et al., 1987d; Pfaller et al., 1988).

In summary, inhibition of specific binding of AAC by anti-MOM72 antibodies and coprecipitation of AAC at the stage 2 site with MOM72 strongly suggest that MOM72 functions as import receptor for the precursor of AAC. The marked inhibition of $A A C$ import by antibodies and Fab fragments against MOM72 (Figures $5 A$ and $5 B$ ) indicate that MOM72 represents the main receptor for mitochon- 


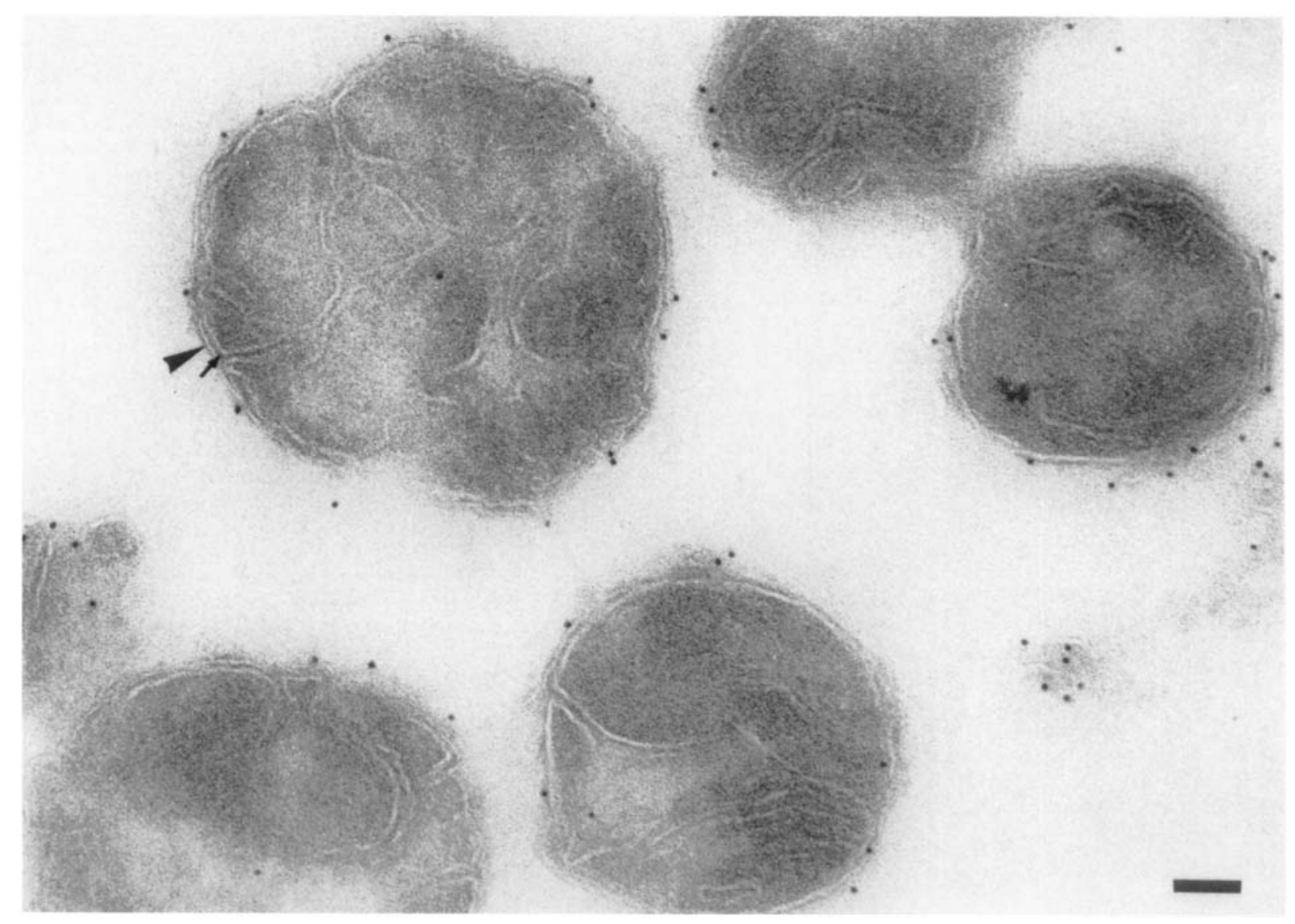

Figure 3. Cryosections of Mitochondria Labeled with Anti-MOM72 Antibodies and Protein A-Gold

Cryosections of mitochondria were prepared, labeled with anti-MOM72 antibodies and protein A-gold particles, and embedded in a mixture of methy! cellulose and ammonium molybdate. It is evident that the bulk of the labeling is on profiles of the outer membrane (arrowhead). The arrow indicates innner membrane. Bar $=100 \mathrm{~nm}$.

drial import of AAC. It remains possible that additional components exist on the mitochondrial surface with a (low) receptor-like activity for AAC.

\section{The Precursor of MOM72 Uses MOM19 As Its Receptor}

A full-length cDNA encoding the precursor of MOM72 was isolated from an N. crassa cDNA library by antibody screening (Hawlitschek et al., 1988). The precursor of MOM72 was expressed by coupled transcription/transiation in rabbit reticulocyte lysate (Figure $8 A$, lane 2). In vitro synthesized MOM72 exhibited the same apparent molecular size as MOM72 immunoprecipitated from mitochondria (Figure $8 \mathrm{~A}$, lane 1) and was specifically recognized by the antibodies directed against MOM72 (Figure 8A, lane 3). This precursor of MOM72 was imported into isolated mitochondria. As expected for import of outer membrane proteins that are not proteolytically processed, the imported protein exhibited the same apparent molecular size as the precursor protein. Pretreatment of mitochondria with protease inhibited import of MOM72 (data not shown). This indicated that import of MOM72 would involve a protease-accessible surface receptor. We thus in- vestigated whether one of the two known receptors, MOM19 and MOM72 itself, functions as import receptor for the precursor of MOM72. Figure $8 \mathrm{~B}$ shows that antibodies against MOM19 prebound to mitochondria inhibited import of MOM72, while antibodies against MOM72 itself, porin or from preimmune sera, did not. This suggests that MOM19 functions as import receptor for the precursor of MOM72.

\section{Discussion}

We report here on the identification of the mitochondrial outer membrane protein MOM72. Antibodies as well as Fab fragments directed against MOM72 selectively inhibited import of AAC into mitochondria. Inhibition occurred at the level of specific binding of AAC to the mitochondrial surface, whereas other transport steps such as insertion into the outer membrane and translocation from the outer membrane into the inner membrane were not affected. Also, AAC remained specifically bound to MOM72 after lysis of mitochondria with detergent. Together, these data argue strongly that MOM72 represents an import receptor for AAC. 


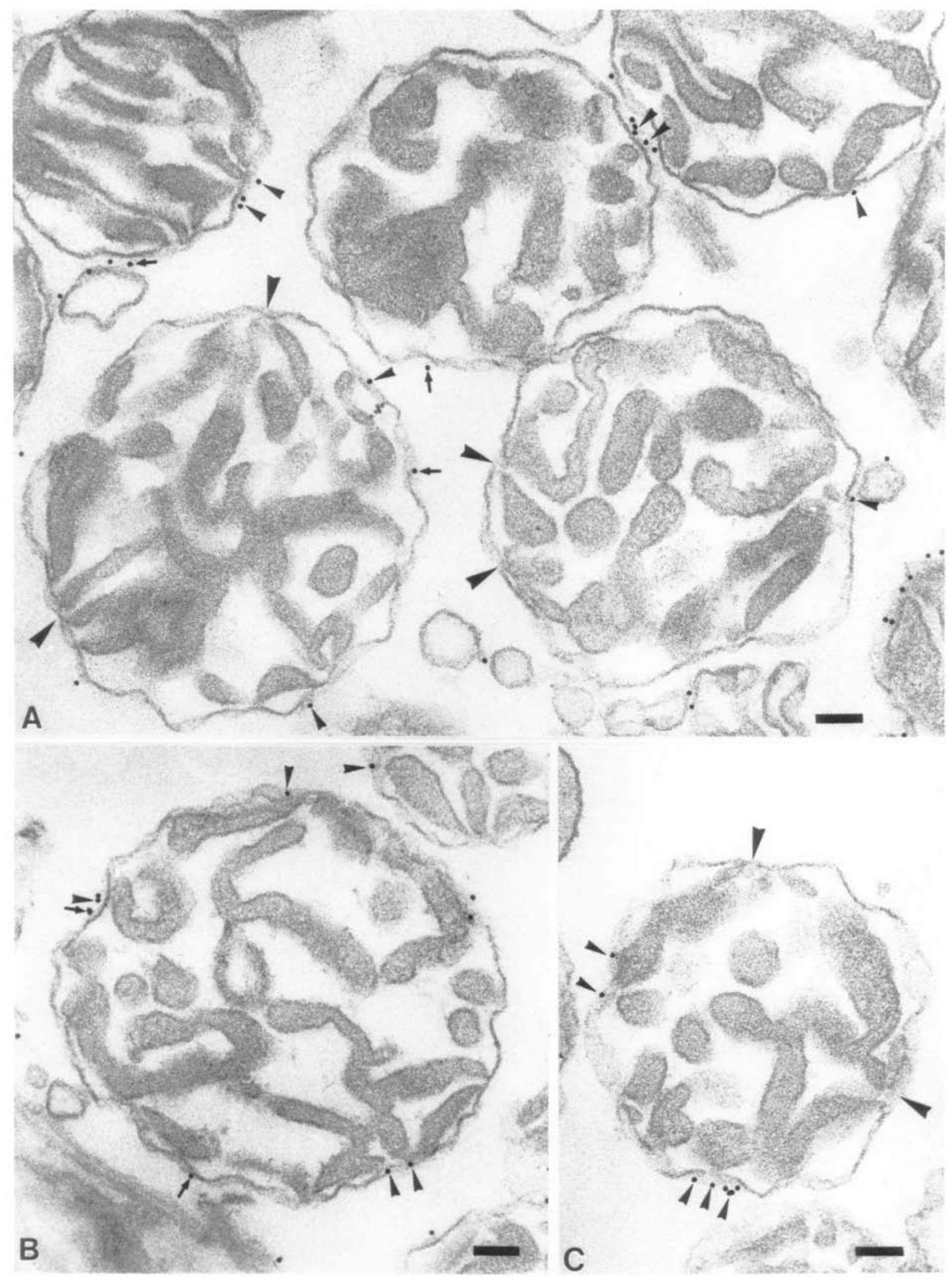

Figure 4. Epon Sections of Mitochondria Prelabeled with Anti-MOM72 Antibodies

Mitochondria were prelabeled with anti-MOM72 lgGs, decorated with protein A-gold particles, and fixed in glutaraldehyde. Plastic sections were prepared. The small arrowheads indicate gold particles positioned on contact sites, the larger arrowheads show unlabeled contact sites, while the arrows indicate some of the gold particles that are apparently not on contact sites. Bars $=100 \mathrm{~nm}$. 

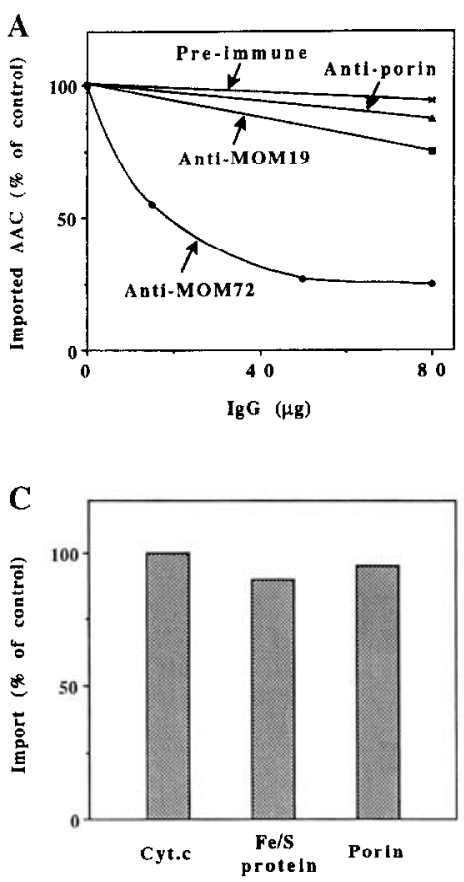
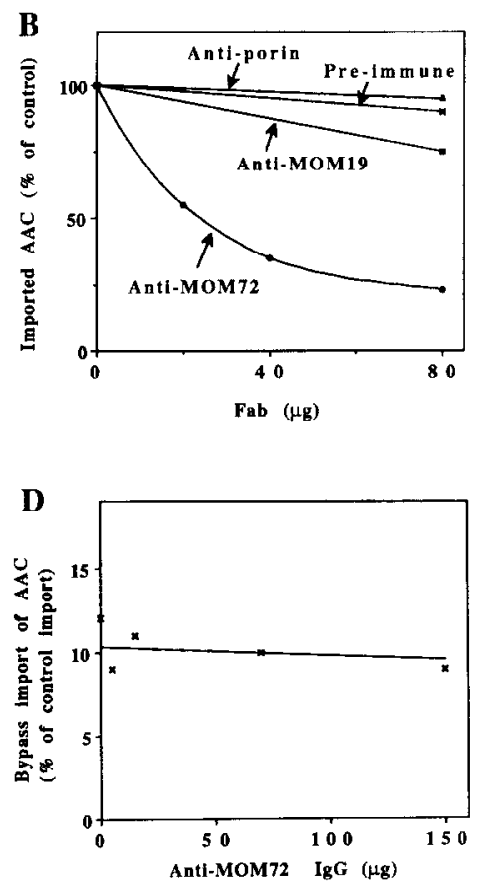

Figure 5. Antibodies against MOM72 Inhibit Import of AAC into Mitochondria

(A) IgGs against MOM72 inhibit import of ADPIATP carrier (AAC). Mitochondria (10 $\mu \mathrm{g}$ of protein) were preincubated with IgGs prepared from either preimmune sera or antisera directed against MOM72, MOM19, and porin for $35 \mathrm{~min}$ at $0^{\circ} \mathrm{C}$ as described (Söllner et al., 1989). Reticulocyte lysate containing $\left[{ }^{35} \mathrm{~S}\right] \mathrm{me}$ thionine-labeled precursor proteins was added and the import mixture was incubated in the presence of K-ascorbate $(8 \mathrm{mM})$ and TMPD $(0.2 \mathrm{mM})$ under standard import conditions (see Experimental Procedures). After treatment with proteinase $K$, mitochondria were reisolated, lysed in SDS-containing buffer, and resolved by SDS-PAGE. Imported AAC was quantified by laser densitometry of the fluorograph of the resulting gel.

(B) Fab fragments against MOM72 inhibit import of AAC. Import was performed as described in (A), except that Fab fragments, instead of IgGs, were prebound to mitochondria. (C) IgGs against MOM72 do not inhibit import of porin, $\mathrm{Fe} / \mathrm{S}$ protein, and apocytochrome $\mathrm{C}$. Prebinding of $\operatorname{lgGs}(80 \mu \mathrm{g})$ directed against the MOM72 protein and import of porin and $\mathrm{Fe} / \mathrm{S}$ protein were performed as described (Söllner et al., 1989). Import of cytochrome c (Cyt.c) was measured by analysis of formation of holocytochrome $c$ as described (Nicholson et al., 1987; Söliner et al., 1989). In parallel samples, IgGs from preimmune sera were used (control).

(D) IgGs against MOM72 do not inhibit bypass import. Mitochondria $(1 \mathrm{mg} / \mathrm{ml})$ were pretreated with trypsin $(20 \mu \mathrm{g} / \mathrm{ml})$ for $20 \mathrm{~min}$ at $0^{\circ} \mathrm{C}$ (Pfaller et al., 1989). IgGs were bound to mitochondria, and import of AAC was performed as described in (A).
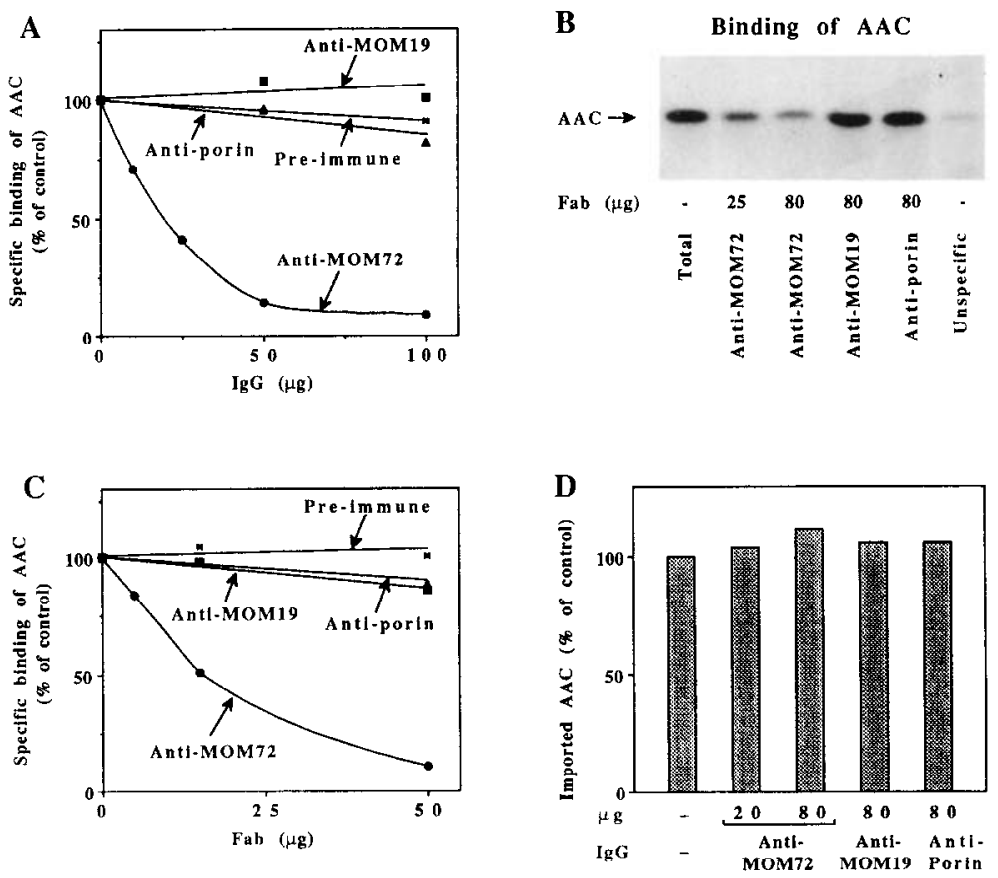

Figure 6. Antibodies against MOM72 Inhibit Specific Binding of AAC to the Mitochondrial Surface

(A) IgGs against MOM72 inhibit specific binding of $A A C$. IgGs were prebound to mitochondria ( $10 \mu \mathrm{g}$ of protein) pretreated with apyrase. Reticulocyle lysate containing [ ${ }^{35}$ S)methionine-labeled AAC was treated with apyrase and added to the mitochondria. The binding reaction was performed as described in Experimental Procedures. Experiments with IgGs that were prepared against a fusion protein between MOM72 and $\beta$-galactosidase expressed in Escherichia coli yielded similar results as the experiments with IgGs prepared against purified MOM72 (M. Kiebler, T. S., N. P., and W. N., unpublished data).

$(B$ and $C$ ) Fab fragments directed against MOM72 inhibit specific binding of AAC. The experiments were performed as described in (A), except that Fab fragments were used instead of IgGs. Total: total amount of AAC bound to mitochondria. Unspecific: AAC bound to mitochondria that had been pretreated with trypsin (20 $\mu \mathrm{g} / \mathrm{ml}$ ).

(D) Insertion of AAC into the outer membrane and translocation into the inner membrane are not inhibited. AAC precursor was bound to the mitochondrial surface as described in Experimental Procedures in the presence of antimycin A and oligomycin. The mitochondria were reisolated, washed in SEM, and resuspended in BSA buffer. IgGs were added, and the mixture was incubated for $20 \mathrm{~min}$ at $0^{\circ} \mathrm{C}$. To initiate completion of import, GTP $(6 \mathrm{mM}), \mathrm{K}$-ascorbate $(8 \mathrm{mM})$, and TMPD $\left(0.2 \mathrm{mM}\right.$ ) were added (Pfanner et al., 1987d). After incubation for $15 \mathrm{~min}$ at $25^{\circ} \mathrm{C}$, the samples were treated with proteinase $\mathrm{K}(150 \mu \mathrm{g} / \mathrm{ml})$. 


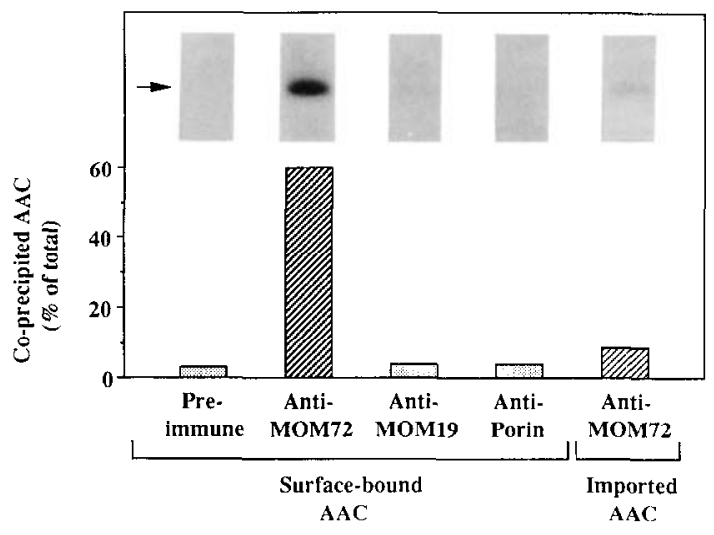

Figure 7. AAC Bound to the Mitochondrial Surface Is Coprecipitated with Antl-MOM72 Antibodies

$A A C$ was either bound to the mitochondrial surface (see Figures $6 A$ and $6 \mathrm{~B}$ and Experimental Procedures) or imported into the inner membrane (see Figures $5 \mathrm{~A}$ and 58 and Experimental Procedures). Following reisolation, the mitochondria were lysed in digitonin-containing buffer as described in Experimental Procedures. Immunoprecipitation was performed using preimmune IgGs or lgGs directed against porin, MOM19, or MOM72. The amount of coimmunoprecipitable AAC is expressed as percent of total radiolabeled AAC in the mitochondrial extracts. The arrow marks coimmunoprecipitated AAC on fluorographs.

Why do mitochondria possess more than one import receptor for precursor proteins? Recent observations indicate that AAC does not only employ a specific surface receptor but also uses a different intramitochondrial sorting pathway, as compared with precursor proteins with amino-terminal targeting signals (K. Mahlke, N. P., J. Martin, A. L. Horwich, F.-U. Hartl, and W. N., submitted) (Figure 9). The latter precursor proteins appear to follow a "conservative" type of sorting: after import via MOM19 and contact sites into the mitochondrial matrix, the proteins use sorting and assembly pathways probably established in prokaryotic ancestors of mitochondria; this includes the ATP-dependent interaction with the heat shock protein hsp60 in the matrix (Hartl et al., 1986, 1987; Cheng et al., 1989; Ostermann et al., 1989; K. Mahlke, N. P., J. Martin, A. L. Horwich, F.U. Hartl, and W. N., submitted). In contrast, $A A C$ follows a nonconservative sorting pathway from the outer membrane into the inner membrane that does not require hsp 60 or measurable levels of ATP (Pfanner et al., 1987d; K. Mahlke, N. P., J. Martin, A. L. Horwich, F.U. Hartl, and W. N., submitted). AAC most likely does not possess a prokaryotic equivalent (Klingenberg, 1985). $A A C$, which contains targeting signals in non-amino-terminal (carboxy-terminal) regions (Pfanner et al., 1987b; Smagula and Douglas, 1988), may represent a class of proteins that was introduced by the eukaryotic cell and thus follows a distinct import pathway.

It has to be emphasized, however, that the import pathway of AAC is not entirely different from that of precursor proteins with amino-terminal targeting sequences. At least two transport steps, insertion into the outer membrane at a general membrane insertion site (general insertion protein) (Pfanner and Neupert, 1987; Pfaller et al., 1988; N. P., T. S., G. G., N. P., and W. N., unpublished data) and
$\mathbf{A}$
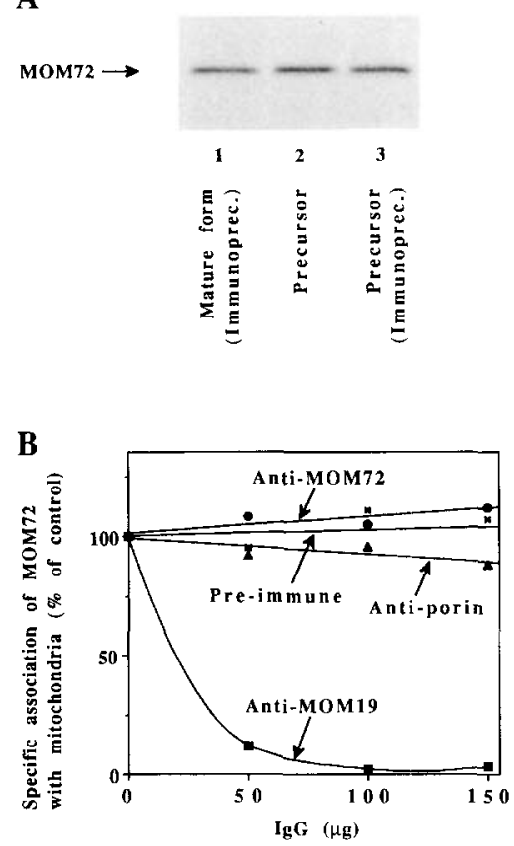

Figure 8. Antibodies against MOM19 Inhibit Specific Association of the Precursor of MOM72 with Mitochondria

(A) Synthesis of the precursor of MOM72. MOM72 was synthesized by coupled transcription/translation in rabbit reticulocyte lysate in the presence of $\left[{ }^{35} \mathrm{~S}\right]$ methionine (reaction 2). Immunoprecipitation (Immunoprec.) with antibodies against MOM72 out of ${ }^{35} \mathrm{~S}$-labeled mitochondria (reaction 1) or reticulocyte lysate containing MOM72 (reaction 3) was performed as described in Figure 1B. The samples were analyzed by SDS-PAGE and fluorography.

(B) Import of MOM72 into mitochondria. Mitochondria were preincubated with IgGs directed against MOM19, MOM72, or porin, or IgGs from preimmune sera as described in Experimental Procedures. The mitochondria were reisolated and washed in SEM buffer containing $100 \mathrm{mM} \mathrm{KCl}$. Precursor of MOM72 was synthesized in rabbit reticulocyte lysate in the presence of ${ }^{35}$ S ]methionine and added to the mitochondria under standard import conditions (see Experimental Procedures). After incubation for $10 \mathrm{~min}$ at $0^{\circ} \mathrm{C}$, the mitochondria were reisolated, washed in SEM (plus $100 \mathrm{mM} \mathrm{KCl}$ ), and subjected to SDS-PAGE. Specific association of MOM72 with mitochondria was analyzed by laser densitometry of the fluorograph; the amounts of MOM72 bound to mltochondria that had been pretreated with trypsin $(20 \mu \mathrm{g} / \mathrm{ml}$ ) (unspecific association; Pfanner et al., 1987c; Söliner et al., 1989) were subtracted.

translocation through contact sites between both mitochondrial membranes (Schleyer and Neupert, 1985; Schwaiger et al., 1987; Pfanner et al., 1987a; Rassow et al., 1989) appear to be common steps for both classes of precursor proteins (Figure 9).

Import of AAC may also involve the $42 \mathrm{kd}$ outer membrane protein that was recently identified in yeast mitochondria (Vestweber et al., 1989). The available data suggest, however, that this $42 \mathrm{kd}$ protein does not represent a surface receptor, as it is obviously not degraded by a treatment of mitochondria with trypsin (Ohba and Schatz, 1987). With chloroplasts, two envelope proteins of $66 \mathrm{kd}$ (Cornwell and Keegstra, 1987) and $30 \mathrm{kd}$ (Pain et al., 1988) seem to be involved in protein import. These proteins may act as receptor sites or represent other components of the import machinery. It is unknown so far if these two pro- 


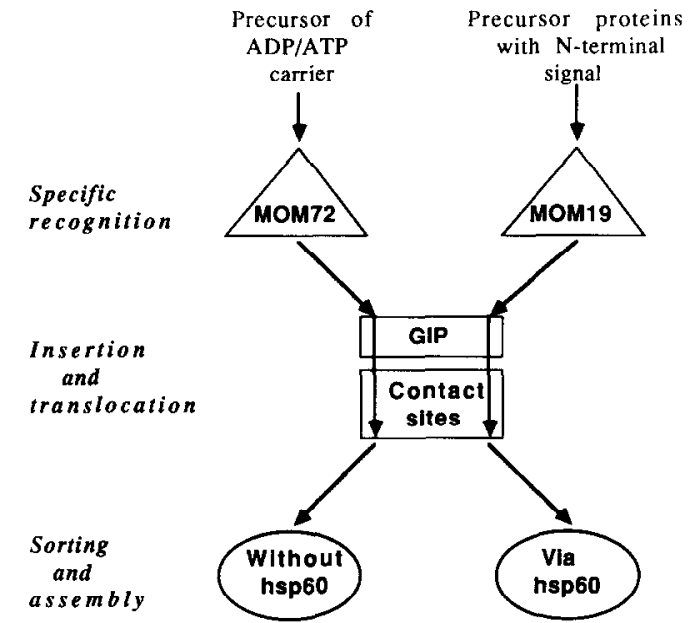

Figure 9. Model on the Targeting and Sorting Pathways of Mitochondrial Precursor Proteins

AAC is thought to represent a class of proteins without prokaryotic equivalent; the precursor protein uses the import receptor MOM72 and is sorted without involvement of the heat shock protein hsp60 (nonconservative sorting). For most precursor proteins with amino-terminal signal sequences, prokaryotic equivalents are known; the precursor proteins are recognized by MOM19 and are sorted via hsp60 (conservative sorting). Insertion into the outer membrane at the general insertion protein (GIP) and translocation at contact sites between both mitochondrial membranes appear to be steps shared by both classes of precursor proteins. The outer membrane protein porin (not shown) was found to interact with MOM19 and GIP prior to assembly into the outer membrane (Söllner et al., 1989; Pfaller et al., 1988); the evolutionary origin of porin is unknown.

teins exhibit a differential specificity for subclasses of precursor proteins.

It is interesting to note that the precursor of MOM72 employs MOM19 as its receptor. This and the finding that most precursor proteins studied use MOM19 (Sollner et al., 1989) suggest that MOM19 might fulfill a function as "master receptor", while MOM72 may possess a more specialized role as receptor for a class of precursor proteins represented by AAC. In addition, MOM72, of which a large hydrophilic domain protrudes into the cytosol (T. S., N. P., and W. N., unpublished data), may perform further functions such as interaction with the cytoskeleton or involvement in self-recognition of mitochondria in connection with fusion and fission processes.

\section{Experimental Procedures}

The following procedures were performed as published previously: growth of N. crassa (wild-type 74A) in the absence or presence of [ ${ }^{35}$ S] sulfate (Schleyer et al., 1982; Sollner et al., 1989); isolation of mitochondria by differential centrifugation (Planner and Neupert, 1985); preparation of mitochondrial outer membranes (Sollner et al., 1989); production of antisera in rabbits, purification of lgGs by protein A-Sepharose chromatography, and preparation of Fab fragments (Söllner et al., 1989); preparation of samples for electron microscopy (Griffiths et al., 1983, 1984; Söllner et al., 1989); synthesis of mitochondrial precursor proteins in rabbit reticulocyte lysate and labeling with ${ }^{35}$ S]methionine (Pelham and Jackson, 1976; Pfaller et al., 1988) by coupled transcription/transiation (Stueber et al., 1984); isolation of a full-length cDNA for MOM72 by screening of an N. crassa cDNA library with antibodies (Young and Davis, 1983; Kleene et al., 1987; Hawlitschek et al., 1988); preincubation of mitochondria with IgGs or Fab fragments for $35 \mathrm{~min}$ at $0^{\circ} \mathrm{C}$ (Söllner et al., 1989); treatment of mitochondria with proteases (Pfaller et al., 1988, 1989; Pfanner and Neupert, 1987); immunoprecipitations and SDS-polyacrylamide gel electrophoresis (SDS-PAGE) (Laemmli, 1970; Schleyer et al., 1982; Pfanner and Neupert, 1985); quantitation of fluorographs by laser densitometry (Pfanner et al., 1987c) using a calibration curve. For coimmunoprecipitation of AAC, the following buffer was used for lysis of mitochondria: $2 \%$ (w/v) digitonin, $250 \mathrm{mM}$ sucrose, $1 \mathrm{mM}$ EDTA, $1 \mathrm{mM}$ phenylmethylsulfonyl fluoride, $10 \mathrm{mM}$ 3-(N-morpholino)propanesulfonic acid (MOPS) adjusted to $\mathrm{pH} 7.2$ with $\mathrm{KOH}$; for incubation of mitochondrial extracts with protein A-Sepharose carrying IgGs, the concentration of digitonin was $0.5 \%(w / v)$, and bovine serum albumin (BSA) $(3 \% \mathrm{w} / \mathrm{v})$ and $\mathrm{NaCl}$ $(100 \mathrm{mM})$ were included; for washing of the immunoprecipitates, BSA was omitted from the buffer.

The import assays consisted of 5\%-30\% (v/v) rabbit reticulocyte lysate containing radiolabeled mitochondrial precursor proteins, $\mathrm{KCl}$ (70 $\mathrm{mM})$, unlabeled methionine $(5 \mathrm{mM})$, mitochondria (10 $\mu \mathrm{g}$ of protein) and BSA buffer (250 mM sucrose, $3 \%$ w/v BSA, $5 \mathrm{mM} \mathrm{MgCl} \mathrm{M}_{2}, 10 \mathrm{mM}$ MOPS/KOH [pH 7.2]), in a final volume of $200 \mu$. Addition of $N, N, N^{\prime}, N^{\prime}$ tetramethylphenylenediamine (TMPD) and potassium ascorbate (to generate a mitochondrial membrane potential) or of antimycin A oligomycin, and valinomycin (to dissipate the membrane potential) was performed as published (Pfanner and Neupert, 1987). Incubation was performed for $7 \mathrm{~min}$ at $25^{\circ} \mathrm{C}$. After the import reaction the mitochondria were treated with proteinase $\mathrm{K}(100 \mu \mathrm{g} / \mathrm{ml})$ for $20 \mathrm{~min}$ at $0^{\circ} \mathrm{C}$. For bind ing of AAC to the mitochondrial surface, reticulocyte lysate and mitochondria were separately pretreated with apyrase $(5 \mathrm{U} / \mathrm{ml}$ ) (Pfanner and Neupert, 1986) for 25 min at $25^{\circ} \mathrm{C}$ or $4^{\circ} \mathrm{C}$, respectively; the binding reactions were performed in the presence of antimycin $A(8 \mu \mathrm{M})$, oligomycin $(20 \mu \mathrm{M})$, and valinomycin $(0.5 \mu \mathrm{M})$ (Ptanner and Neupert. 1987; Pfaller et al., 1988) at the conditions described above (the concentration of $\mathrm{KCl}$ was $125 \mathrm{mM}$ ), then the mitochondria were reisolated and washed with SEM buffer (250 $\mathrm{mM}$ sucrose, $1 \mathrm{mM}$ EDTA, $10 \mathrm{mM}$ MOPS/KOH [pH 7.2]). To determine the amount of specific binding and import, parallel reactions were performed with mitochondria pretreated with trypsin $(20 \mu \mathrm{g} / \mathrm{ml}$; "unspecific" [Pfanner et al., 1987c; Pfaller et al., 1988, 1989; Söllner et al., 1989]), and the values obtained were subtracted from the total amount of binding or import, respectively.

\section{Acknowledgments}

We thank Heinz Horstmann for expert help with electron micrographs and Christine Forster, Ulrike Hanemann, and Brigitte Stelzle for expert technical assistance. We are grateful to Michael Kiebler and Dr. Maximilian Tropschug for help in subcloning the cDNA encoding the MOM72 precursor protein. This work was supported by the Deutsche Forschungsgemeinschaft (Sonderforschungsbereich 184, project B1) and the Fonds der Chemischen Industrie.

The costs of publication of this article were defrayed in part by the payment of page charges. This article must therefore be hereby marked "advertisement" in accordance with 18 U.S.C. Section 1734 solely to indicate this fact.

Received January 8, 1990; revised April 18, 1990.

\section{References}

Arends, H., and Sebald, W. (1984). Nucleotide sequence of the cloned mRNA and gene of the ADP/ATP carrier from Neurospora cressa. EMBO J. 3, 377-382.

Attardi, G., and Schatz, G. (1988). Biogenesis of mitochondria. Annu. Rev. Cell Biol. 4, 289-333.

Blake, M. S., Johnston, K. H., Russel-Jones, G. J., and Gottschlick, E. C. (1984). A rapid, sensitive method for detection of alkaline phosphatase-conjugated anti-antibody on Western blots. Anal. Biochem. 136, 175-179.

Cheng, M. Y., Hartl, F.-U., Martin, J., Pollock, R. A., Kalousek, F., Neu pert, W., Hallberg, E. M., Hallberg, A. L., and Horwich, A. L. (1989) Mitochondrial heat-shock protein hsp60 is essential for assembly of proteins imported into yeast mitochondria. Nature 337, 620-625.

Cornwell, K. L., and Keegstra, K. (1987). Evidence that a chloroplast surface protein is associated with a specific binding site for the precur- 
sor to the small subunit of ribulose-1,5-bisphosphate carboxylase. Plant Physiol. 85, 780-785

Fujiki, Y., Hubbard, A. L., Fowler, S., and Lazarow, P. B. (1982a). Isolation of intracellular membranes by means of sodium carbonate treatment: application to endoplasmic reticulum. J. Cell Biol. 93, 97-102. Fujiki, Y., Fowler, S., Shio, H., Hubbard, A. L., and Lazarow, P. B. (1982b). Polypeptide and phospholipide composition of the membrane of rat liver peroxisomes: comparison with endoplasmic reticulum and mitochondrial membranes. J. Cell Biol. 93, 103-110.

Griffiths, G., Simons, K., Warren, G., and Tokuyasu, K. T. (1983). Immunoelectron microscopy using thin, frozen sections: application to studies of intracellular transport of Semliki Forest virus spike glycoproteins. Meth. Enzymol. 96, 466-485.

Griffiths, G., McDowall, A., Back, R., and Dubochet, J. (1984). On the preparation of cryosections for immunocytochemistry. J. Ultrastruct. Res. 89, 65-78.

Hartl, F.-U., Schmidt, B., Wachter, E., Weiss, H., and Neupert, W. (1986). Transport into mitochondria and intramitochondrial sorting of $\mathrm{Fe} / \mathrm{S}$ protein of ubiquinol-cytochrome c reductase. Cell 47, 939-951. Hartl, F.-U., Ostermann, J., Guiard, B., and Neupert, W. (1987). Successive translocation into and out of the mitochondrial matrix: targeting of proteins to the intermembrane space by a bipartite signal peptide. Cell 51, 1027-1037.

Hartl, F.-U., Pfanner, N., Nicholson, D. W., and Neupert, W. (1989). Mitochondrial protein import. Biochim. Biophys. Acta 988, 1-45.

Hawlitschek, G., Schneider, H., Schmidt, B., Tropschug, M., Hartl, F.-U., and Neupert, W. (1988). Mitochondrial protein import: identification of processing peptidase and of PEP, a processing enhancing protein. Cell 53, 795-806

Kleene, R., Pfanner, N., Pfaller, R., Link, T. A., Sebald, W., Neupert, W., and Tropschug, M. (1987). Mitochondrial porin of Neurospora crassa: cDNA cloning, in vitro expression and import into mitochondria. EMBO J. 6, 2627-2633.

Klingenberg, M. (1985). Principles of carrier catalysis elucidated by comparing two similar membrane translocators from mitochondria, the ADPIATP carrier and the uncoupling protein. Ann. NY Acad. Sci. 456 , 279-288.

Laemmli, U. K. (1970). Cleavage of structural proteins during the assembly of the head of bacteriophage T4. Nature 227, 680-685.

Nicholson, D. W., Köhler, H., and Neupert, W. (1987). Import of cytochrome $c$ into mitochondria: cytochrome $c$ heme lyase. Eur. J. Biochem. 164, 147-157.

Nicholson, D. W., Hergersberg, C., and Neupert, W. (1988). Role of cytochrome $c$ heme lyase in the import of cytochrome $c$ into mitochondria. J. Biol. Chem. 263, 19034-19042.

Ohba, M., and Schatz, G. (1987). Protein import into yeast mitochondria is inhibited by antibodies raised against $45-\mathrm{kd}$ proteins of the outer membrane. EMBO J. 6, 2109-2115.

Ostermann, J., Horwich, A. L., Neupert, W., and Hartl, F.-U. (1989). Protein folding in mitochondria requires complex formation with hsp60 and ATP hydrolysis. Nature 341, 125-130.

Pain, D., Kanwar, Y. S., and Blobel, G. (1988). Identification of a receptor for protein import into chloroplasts and its localization to envelope contact zones. Nature 331, 232-237.

Pelham, H. R. B., and Jackson, A. J. (1976). An efficient mRNA-dependent translation system from reticulocyte lysates. Eur. J. Biochem. $67,247-256$

Pfaller, R., Steger, H. F., Rassow, J., Pfanner, N., and Neupert, W. (1988). Import pathways of precursor proteins into mitochondria: multiple receptor sites are followed by a common membrane insertion site. J. Cell Biol. 107, 2483-2490

Pfaller, R., Pfanner, N., and Neupert, W. (1989). Mitochondrial protein import: bypass of proteinaceous surface receptors can occur with low specificity and efficiency. J. Biol. Chem. 264, 34-39.

Pfanner, N., and Neupert, W. (1985). Transport of proteins into mitochondria: a potassium diffusion potential is able to drive the import of ADPIATP carrier. EMBO J. 4, 2819-2825.

Pfanner, N., and Neupert, W. (1986). Transport of $F_{1}-$ ATPase subunit $\beta$ into mitochondria depends on both a membrane potential and nucleoside triphosphates. FEBS Lett. 209, 152-156.

Pfanner, N., and Neupert, W. (1987). Distinct steps in the import of ADPIATP carrier into mitochondria. J. Biol. Chem. 262, 7528-7536.

Pfanner, N., and Neupert, W. (1989). Transport of proteins into mitochondria. Curr. Opin. Cell Biol. 1, 624-629

Pfanner, N., Hartl, F.-U., Guiard, B., and Neupert, W. (1987a). Mitochondrial precursor proteins are imported through a hydrophilic membrane environment. Eur. J. Biochem. 169, 289-293.

Pfanner, N., Hoeben, P., Tropschug, M., and Neupert, W. (1987b). The carboxyl-terminal two thirds of the ADPIATP carrier polypeptide contains sufficient information to direct translocation into mitochondria. $J$. Biol. Chem. 262, 14851-14854.

Pfanner, N., Müller, H., Harmey, M. A., and Neupert, W. (1987c). Mitochondrial protein import: involvement of the mature part of a cleavable precursor protein in the binding to receptor sites. EMBO J. 6 , 3449-3454

Pfanner, N., Tropschug, M., and Neupert, W. (1987d). Mitochondrial protein import: nucleoside triphosphates are involved in conferring import-competence to precursors. Cell 49, 815-823.

Pfanner, N., Hartl, F.-U., and Neupert, W. (1988). Import of proteins into mitochondria: a multi-step process. Eur. J. Biochem. 175, 205-212.

Rassow, J., Guiard, B., Wienhus, U., Herzog, V., Hartl, F.-U., and Neupert, W. (1989). Translocation arrest by reversible folding of a precursor protein imported into mitochondria. A means to quantitate translocation contact sites. J. Cell Biol. 109, 1421-1428.

Schleyer, M., and Neupert, W. (1984). Transport of ADPIATP carrier into mitochondria: precursor imported in vitro acquires functional properties of the mature protein. J. Biol. Chem. 259, 3487-3491.

Schleyer, M., and Neupert, W. (1985). Transport of proteins into mitochondria: translocational intermediates spanning contact sites between outer and inner membranes. Cell 43, 339-350.

Schleyer, M., Schmidt, B., and Neupert, W. (1982). Requirement of a membrane potential for the posttranslational transfer of protein into mitochondria. Eur. J. Biochem. 125, 109-116.

Schwaiger, M., Herzog, V., and Neupert, W. (1987). Characterization of translocation contact sites involved in the import of mitochondrial proteins. J. Cell Biol. 105, 235-246.

Smagula, C. S., and Douglas, M. G. (1988). ADP-ATP carrier of Saccharomyces cerevisiae contains a mitochondrial import signal between amino acids 72 and 111. J. Cell. Biochem. 36, 323-328

Söllner, T., Pfanner, N., and Neupert, W. (1988). Mitochondrial protein import: differential recognition of various transport intermediates by antibodies. FEBS Lett. 229, 25-29.

Söllner, T., Griffiths, G., Pfaller, R., Pfanner, N., and Neupert, W. (1989). MOM19, an import receptor for mitochondrial precursor proteins. Cell 59, 1061-1070.

Stuart, R. A., Nicholson, D. W., and Neupert, W. (1990). Early steps in mitochondrial protein import: receptor functions can be substituted by the membrane insertion activity of apocytochrome c. Cell 60, 31-43. Stueber, D., Ibrahimi, I., Cutler, D., Dobberstein, B., and Bujard, H (1984). A novel in vitro transcription-translation system: accurate and efficient synthesis of single proteins from cloned DNA sequences. EMBO J. 3, 3143-3148.

Vestweber, D., Brunner, J., Baker, A., and Schatz, G. (1989). A $42 \mathrm{~K}$ outer-membrane protein is a component of the yeast mitochondrial protein import site. Nature 347, 205-209.

Walter, P., and Lingappa, V. R. (1986). Mechanism of protein translocation across the endoplasmic reticulum membrane. Annu. Rev. Cell Biol. 2, 499-516.

Wickner, W. T., and Lodish, H. F. (1985). Multiple mechanisms of protein insertion into and across membranes. Science 230,400-407.

Young, R. A., and Davis, R. W. (1983). Yeast RNA polymerase II genes: isolation with antiboby probes. Science 222, 778-782.

Zimmermann, R., Paluch, U., Sprinzl, M., and Neupert, W. (1979). Cellfree synthesis of the mitochondrial ADPIATP carrier protein of Neurospora crassa. Eur. J. Biochem. 99, 247-252.

Zwizinski, C., Schleyer, M., and Neupert, W. (1983). Transfer of proteins into mitochondria. Precursor to the ADP/ATP carrier binds to receptor sites on isolated mitochondria. J. Biol. Chem. 258, 4071-4074. 